\title{
Existing data sources for clinical epidemiology: The Danish Knee Arthroplasty Register
}

This article was published in the following Dove Press journal:

Clinical Epidemiology

5 May 2012

Number of times this article has been viewed

\author{
Alma B Pedersen' \\ Frank Mehnert' \\ Anders Odgaard ${ }^{2}$ \\ Henrik M Schrøder ${ }^{3}$ \\ 'Department of Clinical Epidemiology, \\ ${ }^{2}$ Department of Orthopedics, \\ Aarhus University Hospital, Aarhus, \\ ${ }^{3}$ Department of Orthopedics, \\ Rigshospitalet, Copenhagen University \\ Hospital, Copenhagen, Denmark
}

Purpose: We described the settings, organization, content, and data quality of the Danish Knee Arthroplasty Register (DKR), as well as the incidence and the first results of the knee replacement procedures captured by the DKR. Our aim was to draw researchers' attention to the DKR and its potential use in clinical epidemiological research.

Patients and methods: The DKR has collected data on all knee replacement procedures performed in Denmark since 1997. The validity of the register was compared with the Danish National Registry of Patients (DNRP). Incidence rate was calculated per 100,000 inhabitants. Implant survival was estimated by Kaplan-Meier method. Cox regression analyses were used to estimate the relative risk (RR) for revision with a $95 \%$ confidence interval (CI).

Results: A total of 62,586 primary knee arthroplasties and 6,683 revisions were registered in the DKR between January 1, 1997 and December 31, 2010. More than 90\% of the private and public hospitals performing knee replacement surgery in Denmark have entered data to the DKR. Registration completeness of primary procedures and revisions has increased since the DKR initiation and was $88 \%$ in 2010 for both procedures, compared with registration in the DNRP. For primary knee arthroplasties, the annual incidence rate increased from 35.8 in 1997 to 155.2 in 2010 per 100,000 inhabitants. Incidence was higher in females than in males during the entire study period, and increased with age for both sexes. The overall implant survival after 14 years was $89 \%$ irrespective of diagnosis for surgery. Male patients had higher revision risk than females, and revision risk decreased with increasing age. Risk for any revision was higher for uncemented implants ( $\mathrm{RR}=1.48 ; 95 \% \mathrm{CI}$ : $1.32-1.66)$, and lower for hybrid implants $(\mathrm{RR}=0.84 ; 95 \% \mathrm{CI}: 0.75-0.95)$ compared to cemented implants. Implant survival did not improve but remained the same throughout the study period when comparing patients operated in the periods 1997-2000 versus 2001-2003, 2004-2006, and 2007-2010.

Conclusion: The DKR is a valuable tool for quality monitoring and research in knee arthroplasty surgery due to the high quality and completeness of prospective, routinely collected data. Large population-based epidemiological studies can be performed in order to study trends as well as risk factors for poor clinical outcome following knee arthroplasty surgery.

Keywords: knee replacement, register, incidence, completeness, implant survival

\section{Introduction}

The Danish Knee Arthroplasty Register (DKR) was initiated by the Danish Orthopaedic Society and the Danish Society for Hip and Knee Arthroplasty Surgery and data collection began on January 1, 1997. The aim of the register is to examine the epidemiology of knee replacement procedures in Denmark, and to monitor and facilitate continuous improvement of knee replacement surgery outcomes on both local and national levels. The DKR contains information on all primary
Correspondence: Alma B Pedersen Department of Clinical Epidemiology, Aarhus University Hospital, Olof Palmes Alle 43-45, 8200 Aarhus N, Denmark Tel +4587 I68 208

Fax +4587167215

Email abp@dce.au.dk 
knee arthroplasty procedures and revisions performed in Denmark. All orthopedic departments report to the database, including public hospital departments, private clinics and departments at private hospitals. Registration of knee arthroplasty procedures was voluntary at first, but became mandatory in June 2006, when the Danish National Board of Health required hospital departments and clinics to report to all relevant national clinical databases.

The Danish national health system provides free access to tax-supported medical care for all Danish residents, a total population of approximately 5.5 million people. Since 1968 , all Danish residents have been assigned a unique 10-digit civil registration number at birth, encoding age, sex, and date of birth. This registration number is always recorded when information on residents is entered into a Danish administrative or medical database. This procedure allows for unambiguous record linkage between surgery data in DKR and a wide range of other databases. ${ }^{1}$ The DKR contains specific surgery-related data which can be expanded by linking with other Danish medical databases.

In the following, we describe the settings, organization, content, and data quality of the DKR, as well as the incidence and the first results of the knee replacement procedures registered in the DKR. Our aim is to draw researchers' attention to the DKR and its potential use in clinical epidemiological research.

\section{Patients and methods Organization of the DKR}

The DKR has a steering committee of orthopedic surgeons representing the Danish Society for Hip and Knee Arthroplasty Surgery and Danish Regions as well as representatives from the Department of Clinical Epidemiology, Competence Centre North, and the Central Denmark Region. The DKR steering committee is responsible for the work of the DKR. The DKR cooperates closely with the Danish Hip Arthroplasty Registry, the Danish Shoulder Arthroplasty Registry and the Danish Cruciate Ligament Registry as a part of the Danish Orthopedic Common Database. The Danish Orthopedic Common Database (including the DKR) obtains its funding from the Danish Regions upon annual application. The total annual costs for the Danish Orthopedic Common Database are about 175,000 EUR. The statistical analyses for the DKR are performed by the Department of Clinical Epidemiology, Competence Centre North. The DKR publishes an annual report, presenting quality indicator data, epidemiological data, results of different implant survival analyses, and trends over time.

\section{Data collection}

Arthroplasty is defined as insertion of any foreign material other than biological material, as compensation for destroyed surface of the knee joint. Primary knee arthroplasty operation is defined as the first knee procedure which involves insertion of total or partial arthroplasty, whereas the revision is defined as any later procedure which involves supplement to, exchange, removal, or modification of the already inserted arthroplasty.

Data for the DKR are collected using a standardized registration form. Since 1997, the departments could either send the paper registration form to the secretary or register data on a disk and forward it to the secretary for entry into the central database. Since 2005, departments have entered data online directly into the DKR using a data entry system called Klinisk Måle System (KMS). At each participating department, a contact person is responsible for DKR data registration and communication with the DKR as well as disseminating information from the DKR in his/her department.

The registered data include pre-, peri-, and postoperative data. The following preoperative data are registered: the patient's civil registration number, the patient's weight, the laterality of the affected knee, primary diagnosis for surgery, previous surgery on the knee, hospital code, and function of the knee according to Charnley classification. ${ }^{2}$ Further, departments have the possibility of registering the preoperative knee status according to American Knee Society Score. ${ }^{3}$

The perioperative data include date of surgery, operation theatre, type of anesthesia, use of antibiotic and antithrombotic prophylactic treatment, surgical approach, preoperative complications, use of drain, implant design and method of fixation for each component, duration of surgery, and component supplement. In case of revision, the number of earlier revisions, the indication for revision, and knee preand postoperative status are also recorded. The decision as to the diagnosis of infection was made by the reporting orthopedic surgeon before or immediately after surgery and thus before the results of the perioperative culture were known. Infections around implant-treated conservative are not recorded in the DKR.

The postoperative data include registration of possible postoperative complications, the patient's satisfaction with treatment and the postoperative knee status according to American Knee Society Score.

For the purpose of implant survival analyses, the DKR has been linked to the Civil Registration System, ${ }^{4}$ which holds information on vital status, date of death, residence, and migration of the entire Danish population since 1968. 
Thus, complete follow-up of all knee arthroplasty patients is possible. We further linked the DKR to the Danish National Registry of Patients, ${ }^{5}$ which contains data on all admissions to public somatic hospitals in Denmark since 1977 and up to 20 discharge diagnoses recorded according to the International Classification of Diseases, ICD-8 and ICD-10. By means of the Danish National Registry of Patients, the rehospitalization rate following knee surgery was calculated.

Comorbidity data are not available in the DKR, but can be extracted from the Danish National Registry of Patients. ${ }^{5}$ Pedersen et $\mathrm{al}^{6}$ linked the DKR to the Danish National Registry of Patients in order to investigate the risk of hospitalization with venous thromboembolism following primary knee arthroplasty. In the same study researchers were able to construct the entire hospitalization history before knee arthroplasty for each patient and use this information as a prognostic factor in regression analyses. ${ }^{6}$

\section{Data quality}

The number of departments performing knee replacement surgery has changed over time due to closing of some, merging of others or the initiation of new private clinics/ departments. In 2010, there were 60 orthopedic departments, including 35 public and 25 private departments performing this surgery, of which 57 reported to the DKR.

The goal of the register is to achieve registration completeness of knee arthroplasties of more than $90 \%$ on both national and department levels, ie, more than $90 \%$ of all knee procedures performed in Denmark should be reported in the DKR. To identify missing procedures, the data entered into the DKR are analyzed every 3 months using the Danish National Registry of Patient as a gold standard. Lists with civil registration numbers for all missing procedure registrations have afterwards been sent to each orthopedic department with a request for data entry.

The entered data are regularly subject to missing value control for all variables included in the dataset. In addition, checks for coding errors are continuously performed for several of the most important variables, such as date of surgery, laterality and type of procedures, and implant design. Several logical checks are incorporated in the online registration system.

\section{Quality indicators}

In 2006, the steering committee proposed the implementation of several quality indicators in order to measure the quality of care provided by the hospitals to knee arthroplasty patients. The aim was to create awareness among health care professionals about the extent to which the completion and outcomes of the knee arthroplasty are in line with the standards expected from a well-functioning health care system. Quality indicators are intended to be used by departments and hospitals in order to improve the quality of knee arthroplasty treatment at their own department and compare their results with the results from other departments and hospitals, as well as national average results. A focus area covering six quality indicators was proposed at the beginning: perioperative complication, follow-up after primary arthroplasty, patient's satisfaction, improvement in knee status, implant survival after primary arthroplasty, and mortality within 90 days of surgery. An algorithm for calculation of indicators has been developed using already available data in the DKR. The quality indicators were optimized in 2010 with the removal of some and inclusion of new indicators. Indicator perioperative complication, for example, has been removed because of difficulties in interpreting the departments' results, ie, the low perioperative complication rate could represent the reality, but could also be the result of poor registration of complications. Since 2010, the set of indicators has included rehospitalization within 30 days of primary surgery irrespective of medical reason, revision rate within 1 year of primary surgery, revision rate within 2 years of primary surgery, revision rate within 5 years of primary surgery, and mortality within 90 days of primary surgery. For calculation of rehospitalization within 30 days of surgery, the DKR has been linked to the Danish National Registry of Patients, extracting the information on all hospitalizations to public somatic hospitals in Denmark irrespective of diagnosis. Rehospitalization is a measure of complication following knee surgery, as the hypothesis is that the hospitalization within 30 days is most likely related to surgery itself.

\section{Statistics}

The registration completeness for primary knee arthroplasty and revisions was assessed using the Danish National Registry of Patients as a reference. Since the civil registration number is recorded in all Danish databases, the estimation of completeness is possible on an individual level. Completeness in the DKR was defined as the number of procedures registered in the DKR divided by the number of procedures registered either in the DKR or the Danish National Registry of Patients. To estimate confidence intervals and compare proportions, we relied on the normal approximation of the binominal distribution. $P$-values less than 0.05 were considered statistically significant.

We used the StatBank Denmark ${ }^{7}$ to obtain information on the population size by each calendar year to be able to 
calculate the annual overall incidence rates of primary knee procedures as followed; the number of procedures by calendar year divided by the total number of Danish residents by calendar year. In addition, age- and sex-specific incidence rates have been calculated.

Implant survival was estimated by use of the KaplanMeier method with 95\% confidence intervals (95\% CI). Outcome was defined as revision due to any cause. Cox regression analyses was used to estimate hazard ratios as a measure of relative risk (RR) for revision with $95 \%$ $\mathrm{CI}$, adjusting for few prognostic factors. For the purpose of implant survival analyses, primary knee replacement procedures were followed until a revision was registered in the DKR. Otherwise, patients were followed until death, emigration or end of study period, whichever came first. Revisions registered in the DKR that could not be linked to a primary knee procedure in the DKR were excluded from the implant survival analyses.

Registration in the DKR is approved by the National Board of Health and the Danish Data Protection Agency (J No 200758-0016) and the current study is approved by the Danish Data Protection Agency (J No 2012-41-0137). All statistical analyses were performed using a statistical software package (version 9.1.3; SAS Institute Inc, Cary, NC).

\section{Results}

A total of 62,586 primary knee arthroplasties and 6683 revisions were registered in the DKR between January 1, 1997 and December 31, 2010. The number of both knee procedures has increased during the DKR registration with a minor decline in 2010 (Table 1). The proportion of procedures performed at private clinics and hospitals has increased constantly from 1997 to 2008 , accounting for only $5 \%$ of all procedures in the period 1997 to about $27 \%$ in 2008 . After that, the proportion of procedures performed at private clinics and hospitals dropped to $17 \%$ in 2009 and 14\% in 2010.

\section{Data quality}

The register coverage has been above $90 \%$ in the entire study period. Thus, each year more than $90 \%$ of private and public

Table I Number of knee arthroplasty procedures registered in the Danish Knee Arthroplasty Registry, period 1997-2010

\begin{tabular}{lllllll}
\hline $\begin{array}{l}\text { Type of } \\
\text { surgery }\end{array}$ & $\begin{array}{l}1997- \\
2000\end{array}$ & $\begin{array}{l}200 I- \\
2007\end{array}$ & 2008 & 2009 & 2010 & Total \\
\hline $\begin{array}{l}\text { Primary } \\
\text { arthroplasty (n) }\end{array}$ & 7368 & 31,865 & 7107 & 8347 & 7899 & 62,586 \\
\begin{tabular}{l} 
Revision (n) \\
\hline
\end{tabular} & 922 & 3012 & 803 & 993 & 953 & 6683 \\
\hline
\end{tabular}

hospitals performing knee replacement surgery entered data into the DKR.

Registration completeness of primary procedures and revisions increased from $76.6 \%$ in 1997 to $88 \%$ in 2010 for primary procedures and from $56.7 \%$ in 1997 to $88 \%$ in 2010 for revisions, compared with registration in the Danish National Registry of Patients.

Missing values to control for variables included in the dataset showed that in more than $95 \%$ of registered cases, the value for each variable is entered. Registration completeness continuously increased not only from 2006, when registration in all national clinical databases became mandatory but from 1997 when the DKR was initiated. Nevertheless, with the mandatory registration rules, patient acceptance was no longer necessary in order to register the procedures in the DKR. In addition, the steering committee strongly refers to the surgeons' consciousness as well as registration rules, when collecting information on missing procedure registration, since financial support to the DKR is directly dependent on registration completeness and coverage.

\section{Incidence}

For primary knee arthroplasties, the annual incidence rate increased from 35.8 in 1997 to 155.2 in 2010 per 100,000 inhabitants. Incidence was higher for females compared to males during the entire study period (Figure 1). The incidence increased with age for both sexes, being highest in the age group 70-79 years (806.2 for females and 623.9 for males per 100,000 inhabitants), and then decreasing with age (Figure 2).

\section{Demographics}

The majority of patients $(66.5 \%)$ are between 60 and 79 years old at the time of primary knee arthroplasty. There was a slight decrease in the mean age at operation, from 69 years in 1997 to 67.2 in 2010. The female-to-male ratio has changed slightly over time for primary procedures. For all procedures, the proportion of female patients was $66.8 \%$ in 1997 decreasing to $58.5 \%$ in 2010 .

The most common diagnosis for primary knee arthroplasty was primary osteoarthritis, followed by secondary osteoarthritis (Table 2). The proportion of primary arthroplasties due to rheumaotid arthritis decreased from $7.7 \%$ in $1997-2000$ to $1.9 \%$ in 2010 , which is an interesting observation (Table 2).

Three quarters of all primary procedures were performed in regional (spinal or epidural) anesthesia and 20\% received general anesthesia. The most frequent surgical approach used was midline through the quadriceps tendon $(60.7 \%)$ followed by 


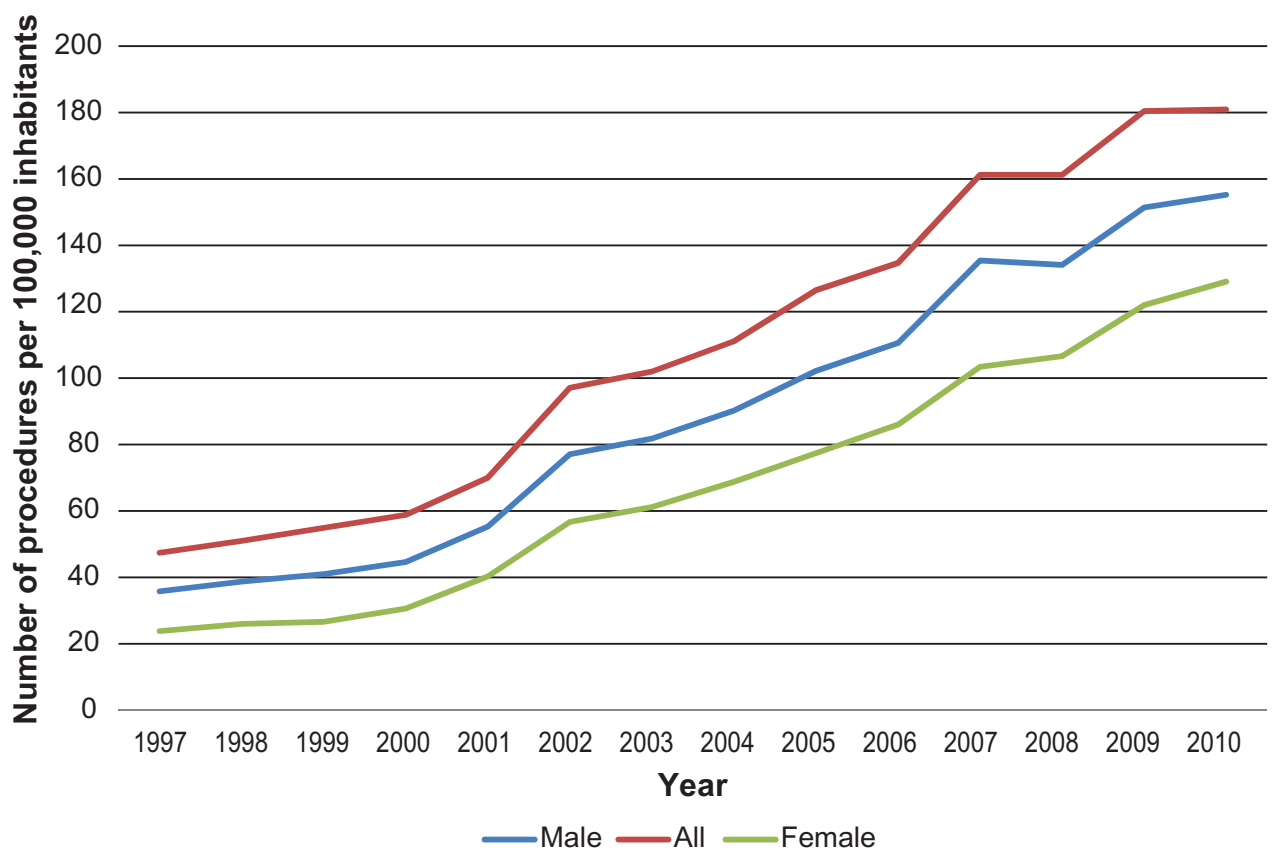

Figure I Annual incidence rates of primary knee arthroplasty procedures per 100,000 inhabitants (on y-axis) in Denmark in the period I997-2010 (on x-axis).

the medial parapatellar approach through the quadriceps tendon (26.3\%). Duration of primary surgery has become shorter during the study period; thus, the average duration of surgery fell from 91.2 minutes in 1997 to 69.5 minutes in 2010.

From 2000 to 2008, the use of uncemented and hybrid primary knee arthroplasties decreased constantly while the use of cemented knee arthroplasties increased. In 2009 and 2010, the use of hybrid implant increased again whereas use of uncemented implants continued to decrease. During the entire study period, a total of 49,107 (78.6\%) procedures were cemented, whereas $4721(7.5 \%)$ and $7786(12.4 \%)$ were uncemented and hybrid primary procedures, respectively.

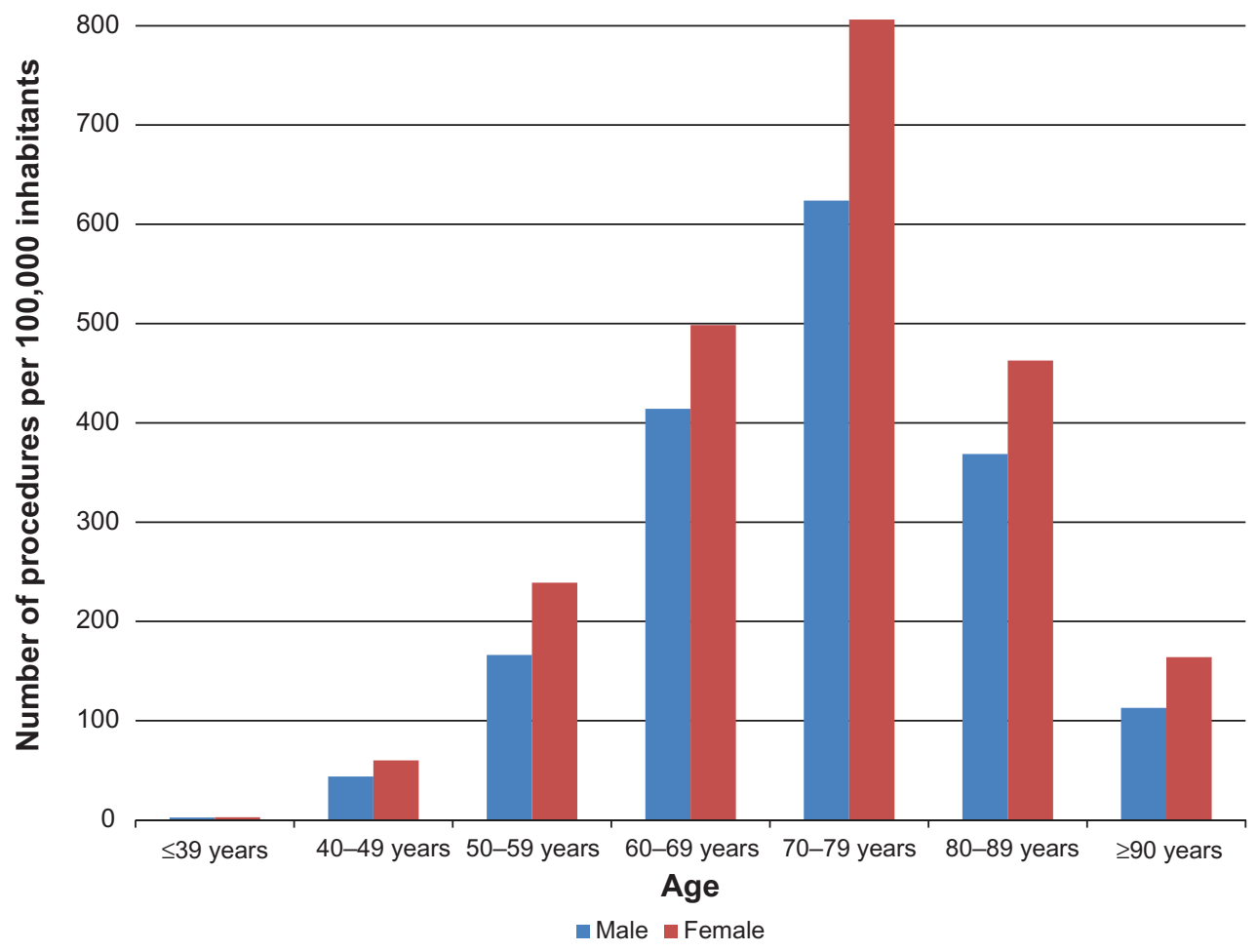

Figure 2 Incidence rates of primary knee arthroplasty procedures per 100,000 inhabitants (on y-axis) in Denmark according to specific age and sex (on x-axis). 
Table 2 Diagnosis for primary knee arthroplasty registered in the Danish Knee Arthroplasty Register, 1997-2010

\begin{tabular}{|c|c|c|c|c|c|c|c|c|c|c|c|c|}
\hline \multirow[t]{2}{*}{ Diagnosis* } & \multicolumn{2}{|c|}{$1997-2000$} & \multicolumn{2}{|c|}{$200 I-2007$} & \multicolumn{2}{|l|}{2008} & \multicolumn{2}{|l|}{2009} & \multicolumn{2}{|l|}{2010} & \multicolumn{2}{|l|}{ Total } \\
\hline & $\mathbf{n}$ & $\%$ & $\mathbf{n}$ & $\%$ & $\mathbf{n}$ & $\%$ & $\mathbf{n}$ & $\%$ & $\mathbf{n}$ & $\%$ & $\mathbf{n}$ & $\%$ \\
\hline Primary osteoarthritis & 5.690 & 77.3 & 26.269 & 82.7 & 6.208 & 87.9 & 7.185 & 86.6 & 6.774 & 86.2 & 52.126 & 83.6 \\
\hline Secondary osteoarthritis & 741 & 10.1 & 3409 & 10.7 & 617 & 8.7 & 796 & 9.6 & 854 & 10.9 & 6.417 & 10.3 \\
\hline Rheumatoid arthritis & 564 & 7.7 & 1173 & 3.7 & 159 & 2.3 & 164 & 2.0 & 153 & 1.9 & 2.213 & 3.5 \\
\hline $\begin{array}{l}\text { Sequelae after fracture } \\
\text { of tibia condyle }\end{array}$ & 201 & 2.7 & 588 & 1.9 & 84 & 1.2 & 90 & I.I & 101 & 1.3 & 1.064 & 1.7 \\
\hline Other diagnoses & 160 & 2.2 & 474 & 1.5 & 82 & 1.2 & 107 & 1.3 & 114 & 1.5 & 937 & 1.5 \\
\hline Sequelae after other arthritis & 67 & 0.9 & 229 & 0.7 & 39 & 0.6 & 54 & 0.7 & 61 & 0.8 & 450 & 0.7 \\
\hline $\begin{array}{l}\text { Sequelae after fracture } \\
\text { of femoral condyle }\end{array}$ & 54 & 0.7 & 161 & 0.5 & 18 & 0.3 & 31 & 0.4 & 27 & 0.3 & 291 & 0.5 \\
\hline $\begin{array}{l}\text { Sequelae after fracture } \\
\text { of patella }\end{array}$ & 20 & 0.3 & 100 & 0.3 & 14 & 0.2 & 23 & 0.3 & 20 & 0.3 & 177 & 0.3 \\
\hline Hemophilia & 9 & 0.1 & 13 & 0.0 & 3 & 0.0 & I & 0.0 & 0 & 0.0 & 26 & 0.0 \\
\hline Total & 7.363 & 100.0 & 31.767 & 100.0 & 7.063 & 100.0 & 8.295 & 100.0 & 7.856 & 100.0 & 62.344 & 100.0 \\
\hline
\end{tabular}

Notes: *Several diagnoses could be registered for the same primary procedure.

In addition, $1.5 \%$ of implants were registered with unknown fixation.

Of all primary arthroplasties, 57,121 (91.3\%) were total knee replacements, and 4636 (7.4\%) were medial unicompartmental knees. In the total study period, 65 different femur and 72 different tibia components were used. Table 3 summarizes the most common used femur and tibia components.

In revision surgery patients, age and sex distribution follow the same pattern as seen for the primary procedures. In 1997-2010, aseptic loosening was registered in the DKR as a main cause of revision in 2036 of all revision cases (30.7\%). Other reasons for revision are listed in Table 4. It is worth noticing the reduction in proportion of revisions due to aseptic loosening, which fell from $33.4 \%$ in $1997-2000$ to $24.4 \%$ in 2008 . At the same time, there was a statistically significant increase in the proportion of revisions due to deep infection from $16.5 \%$ in $1997-2000$ to $31.8 \%$ in 2008. Nevertheless, this changed slightly in 2009 and 2010.

\section{Quality indicators}

The proportion of primary knee arthroplasty patients who were rehospitalized within 30 days of surgery irrespective of reason increased from $6.8 \%$ in 1999 to $7.8 \%$ in $2004,9.3 \%$ in 2007 , and $10.4 \%$ in 2008 , falling to $8.7 \%$ in 2009 . The proportion of rehospitalized patients varied considerably between hospitals in all the years, ranging, eg, from $0 \%$ to $25 \%$ in 2009 .

Revision rate within 1 year of primary surgery increased slightly in the study period from $1.3 \%$ for patients operated in 1999 to $2.3 \%$ for those operated in 2009 . Revision rate within 2 years of primary surgery increased likewise being $2.3 \%$ for patients operated in 1999 and $4.7 \%$ for patients operated in 2008. Regarding revision rate within 5 years, we observed a U-shaped development, as it was $6.3 \%$ for patients operated in 1998, 4.8\% for those operated in 2001, and $6.6 \%$ for those operated in 2005 . Revision rates are presented in Figure 3.

Table 3 The most-commonly used femoral and tibia components for primary knee arthroplasty registered in the Danish Knee Arthorplasty Arthroplasty Registry, 1997-2010

\begin{tabular}{|c|c|c|}
\hline & $\mathbf{n}$ & $\% *$ \\
\hline \multicolumn{3}{|l|}{ Femoral components } \\
\hline $\begin{array}{l}\text { PFC Sigma Cruciate-Retaining } \\
\text { (Johnson and Johnson) }\end{array}$ & 15.225 & 24.3 \\
\hline $\begin{array}{l}\text { AGC V2 Universal } \\
\text { (Biomet) }\end{array}$ & 11.590 & 18.5 \\
\hline $\begin{array}{l}\text { NexGen CR } \\
\text { (Zimmer) }\end{array}$ & 7.209 & 11.5 \\
\hline $\begin{array}{l}\text { PFC Sigma Cruciate-Substituting } \\
\text { (Johnson and Johnson) }\end{array}$ & 5.588 & 8.9 \\
\hline $\begin{array}{l}\text { Vanguard CR } \\
\text { (Biomet) }\end{array}$ & 2.905 & 4.6 \\
\hline $\begin{array}{l}\text { Oxford Phase III } \\
\text { (Biomet) }\end{array}$ & 2.062 & 3.3 \\
\hline Tibia components & $\mathbf{n}$ & $\%$ \\
\hline $\begin{array}{l}\text { AGC V2 } \\
\text { (Biomet) }\end{array}$ & 1.917 & 19.0 \\
\hline $\begin{array}{l}\text { PFC Modular } \\
\text { (Johnson and Johnson) }\end{array}$ & 11.593 & 18.5 \\
\hline $\begin{array}{l}\text { NexGen CR } \\
\text { (Zimmer) }\end{array}$ & 6.333 & 10.1 \\
\hline $\begin{array}{l}\text { PFC Sigma Rotating Platform } \\
\text { (Johnson and Johnson) }\end{array}$ & 3.781 & 6.0 \\
\hline $\begin{array}{l}\text { PFC Sigma Cruciate-Retaining } \\
\text { (Johnson and Johnson) }\end{array}$ & 2.995 & 4.8 \\
\hline $\begin{array}{l}\text { Vanguard CR } \\
\text { (Biomet) }\end{array}$ & 2.830 & 4.5 \\
\hline
\end{tabular}

Notes: *Percentages are calculated as proportions, with the nominator numerator containing the number of uses of the particular component used and the denominator containing the total number of primary arthroplasty procedures in the period 1997-2010. Abbreviations: AGC, anatomical femoral component; CR, cruciate retaining; PFC, posterior fixed component. 
Table 4 Indication for revision of primary knee arthroplasty registered in the Danish Knee Arthroplasty Registry, 1997-20I0

\begin{tabular}{|c|c|c|c|c|c|c|c|c|c|c|c|c|}
\hline \multirow[t]{2}{*}{ Indication* } & \multicolumn{2}{|c|}{$1997-2000$} & \multicolumn{2}{|c|}{$200 I-2007$} & \multicolumn{2}{|c|}{2008} & \multicolumn{2}{|c|}{2009} & \multicolumn{2}{|c|}{2010} & \multicolumn{2}{|c|}{ Total } \\
\hline & $\mathbf{n}$ & $\%$ & $\mathrm{n}$ & $\%$ & $\mathbf{n}$ & $\%$ & $\mathbf{n}$ & $\%$ & $\mathbf{n}$ & $\%$ & $\mathrm{n}$ & $\% * *$ \\
\hline Aseptic loosening & 307 & 33.3 & 987 & 32.8 & 196 & 24.4 & 273 & 27.5 & 273 & 28.6 & 2.036 & 30.7 \\
\hline Pain without loosening & 204 & 22.1 & 607 & 20.2 & 139 & 17.3 & 147 & 14.8 & 159 & 16.7 & 1.256 & 20.4 \\
\hline $\begin{array}{l}\text { Secondary insertion of } \\
\text { patella component }\end{array}$ & 177 & 19.2 & 235 & 7.8 & 50 & 6.2 & 61 & 6.1 & 41 & 4.3 & 564 & 17.7 \\
\hline Deep infection & 152 & 16.5 & 578 & 19.2 & 255 & 31.8 & 287 & 28.9 & 246 & 25.8 & 1.518 & 15.2 \\
\hline Knee instability & 145 & 15.7 & 556 & 18.5 & 139 & 17.3 & 175 & 17.6 & $17 \mid$ & 17.9 & 1.186 & 14.5 \\
\hline Polyethylene wear, tibia & 115 & 12.5 & 247 & 8.2 & 34 & 4.2 & 39 & 3.9 & 41 & 4.3 & 476 & 11.5 \\
\hline Polyethylene wear, patella & 83 & 9.0 & 171 & 5.7 & 24 & 3.0 & 19 & 1.9 & 23 & 2.4 & 320 & 8.3 \\
\hline Other & 88 & 9.5 & 354 & 11.8 & 88 & 11.0 & 145 & 14.6 & 128 & 13.4 & 803 & 8.8 \\
\hline
\end{tabular}

Notes: *Several indications could be registered for the same revision procedure. **Percentages are calculated as proportions, nominator with the numerator containing the number of instances of a particular indication registered in a particular time period and the denominator containing the total number of revisions performed in the same time period.

\section{Implant survival - first results}

The overall implant survival after 14 years was $89 \%$ in primary arthroplasty patients irrespective of diagnosis for surgery with the first revision due to any cause as outcome. We found a slight difference between males and females in the risk for any revision in the period 1997-2010. Thus, the RR was 1.09 (95\% CI: 1.01-1.18) for males vs females, adjusted for age. Patients older than 76 years and between 66 and 76 years had lower RR for any revision compared with patients younger than 66 years. Thus, the relative risks adjusted for sex were 0.40 (95\% CI: 0.35-0.44) for patients aged more than 76 years and 0.60 (95\% CI: 0.55-0.66) for those between 66 and 76 years of age compared with younger patients.
Regarding implant survival in relation to fixation technique, uncemented implants were associated with higher risk for any revision $(\mathrm{RR}=1.48 ; 95 \% \mathrm{CI}: 1.32-1.66)$, whereas hybrid implants lead to lower risk for any revision $(\mathrm{RR}=0.84 ; 95 \% \mathrm{CI}$ : 0.75-0.95) compared to cemented implants. Finally, the DKR revealed no difference in implant survival between patients operated in the periods 2001-2003, 2004-2006, and 2007-2010 compared to patients operated in 1997-2000 (Figure 4).

\section{Discussion Data quality}

In 2010, the registration completeness in the DKR was $88.0 \%$ for primary procedures, which is lower than

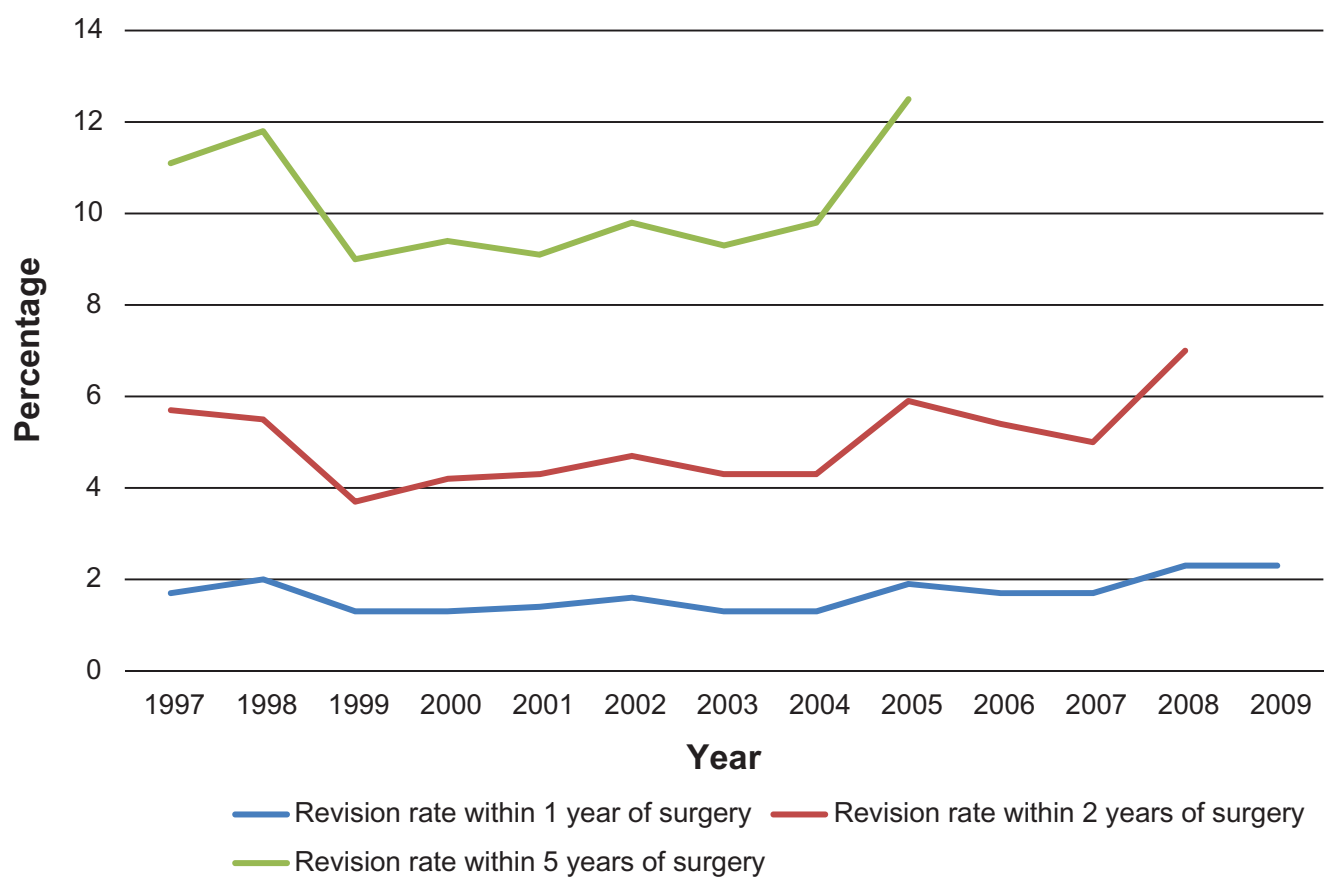

Figure 3 Revision rates in Denmark within I, 2, and 5 years of primary knee arthroplasty procedures in percentages (on y-axis) for patients operated on in the period 1997-2010 (on x-axis). 


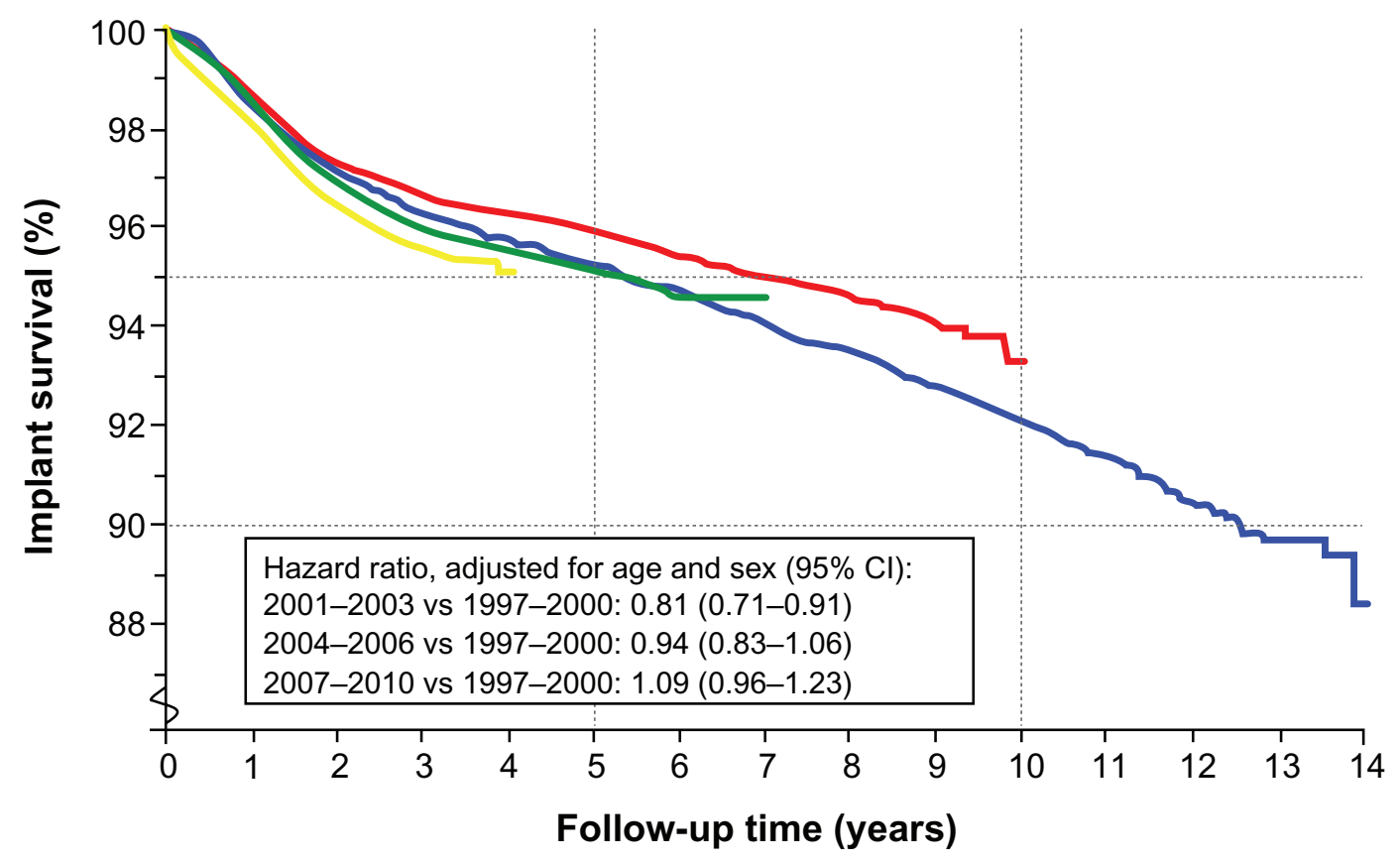

$$
\begin{aligned}
\text { Years of surgery } & -1997-2000(n=7117) \quad-2001-2003(n=9588) \\
-2004-2006(n=13,076) & -2007-2010(n=26,915)
\end{aligned}
$$

Figure 4 Survival of primary total knee arthroplasties according to years of surgery. Endpoint: first revision due to any cause.

Abbreviation: $\mathrm{Cl}$, confidence interval.

previously reported registration completeness of $99 \%$ and more than $90 \%$ for primary knee procedures in Norway and Sweden, respectively. ${ }^{8,9}$ One reason for this discrepancy could be the fact that the Norwegian completeness study was not based on an individual matching of patients registered in a joint registry and a national registry of patients. Another reason may be the differences in coding practice between countries and the number of coding errors. The advantage of using DKR data, although some procedures are missing, is the detailed information on surgery and patient related factors, including a number of prognostic factors important for studying different outcomes. This detailed information is not available in other Danish medical databases. Detailed surgery and patient related data are usually available in clinical studies initiated by one or several departments, but these studies may suffer from lack of power. Lower registration completeness may have meant that studies of incidence provided more conservative estimates. However, lower registration completeness would not have substantial impact on relative risk estimates, because lack of registration is nondifferential, ie, independent of the registration of outcome of interest due to prospective registration of data.

Registration completeness of revision is reported to be higher (97\%) in the Norwegian knee arthroplasty registry and lower (80\%) in the Swedish knee arthroplasty registry than in the DKR (88\%). ${ }^{8,10}$ Robertsson et a ${ }^{10}$ did additional analyses on Swedish knee registry data accounting for the missing revisions and suggested that the overall conclusions about revision risk based on the arthroplasty registry did not change substantially. Survival analyses used in the registry reports are usually based on the Kaplan-Meier method and, due to the existence of competing risks, implant survival would be overestimated. Further, lack of registration of revision is unlikely to be associated with registration of primary procedures, resulting in relative risk estimates close to null, thus of no difference to the groups we compared.

High registration completeness and very few missing values for variables included in the dataset increase the validity of the DKR. However, the proportion of patients correctly registered in the DKR needs to be examined further through the review of medical records and radiographs.

\section{Incidence}

The steady increase in the incidence rates for primary knee arthroplasties found in our study appears to be consistent with the reports from a number of other countries reported in slightly different study periods. ${ }^{11-13}$ Several factors might be responsible for the increase in incidence rates such as the aging population as well as changing clinical decisions for 
performing knee arthroplasty on a wider patient population including very young or very old patients and patients with severe comorbidities. Nevertheless, improvement in surgical technique has to a large extent also contributed to an increase in knee arthroplasty incidence. Two studies predicted the increase in knee arthroplasty incidence until 2030 by $673 \%$ in the United States ${ }^{14}$ and $33 \%$ in Sweden, ${ }^{13}$ using different future scenarios. There is no doubt that the incidence in Denmark will to some extent follow these predictions and will thus represent a serious economic and staff resources challenge for the health care system.

A substantial increase in incidence of knee procedures at private hospitals in 2008 could be explained by the general strike of nurses during several months of 2008 at public hospitals. In addition, the Danish government passed a bill guaranteeing that patients in need of surgery should not have to wait more than 1 month. Both these incidents resulted in patients streaming from public to private hospitals in 2008. Thus, we expected a decrease in the proportion of patients operated on private hospitals in 2009 and 2010, which actually did happen.

\section{Demographics}

We observed an increase in the proportion of knee arthroplasties for patients with primary osteoarthritis, which is in accordance with findings from several countries during the last $10-15$ years. ${ }^{9,15}$ In the same period, we observed a decline in the proportion of knee arthroplasties in patients with rheumatoid arthritis, although the absolute number of these patients was constant throughout the study period. Studies from several countries have reported a similar decline in the incidence of joint replacement surgery due to rheumatoid arthritis. ${ }^{15-17}$ The authors speculated on possible reasons for this trend, including the improvement of medical treatment introducing methotrexate in the 1980s and changes in severity of rheumatoid arthritis, which could be the focus of future research in the DKR.

The increase in proportion of revisions due to deep infection seen in Denmark has been reported in other countries for both knee and hip surgery patients. ${ }^{18-21}$ Orthopedic surgeons may be more prone to treat implant infection with surgery than with medical treatment, or the medical treatment may be less effective than it was some years ago due to occurrence of resistant bacterial strains. In addition, the changes in patient comorbidity profiles (eg, increased proportion of knee arthroplasty patients with diabetes and obesity over time) and indications for surgery (eg, lower threshold for surgery) may in part explain our findings.
Although the DKR does not include detailed data on, eg, causative agent of deep infections and treatment, the DKR can still contribute to the future understanding of this trend by combining the DKR data with laboratory ${ }^{22}$ and microbiological data, ${ }^{23}$ as well as hospital discharge data ${ }^{5}$ available in Denmark.

\section{Quality indicators}

The rehospitalization rate of less than $10 \%$ seen in our study is similar to that reported by a multinational observational study from 13 countries worldwide. ${ }^{24}$ The majority of rehospitalization was due to cardiovascular complications, wound healing or infection, reoperation, and pneumonia. The increase in rehospitalization rate following knee replacement surgery seen over the last decade in Denmark could be due to changes in patient comorbidity profiles and threshold for surgery, as discussed above. Pedersen et $\mathrm{al}^{6}$ reported on increase in venous thromboembolism rate following knee replacement since 1997, which could partly explain our findings. Given the decline in the length of hospitalization for knee arthroplasty seen in Denmark ${ }^{25}$ as well as improvement in the diagnostic management of patients, ${ }^{26}$ our finding may not be surprising after all.

\section{Implant survival - first results}

The overall implant survival after 14 years is similar to implant survival reported from other knee registries. ${ }^{11,27-29}$ Our findings of increased risk for revision among males versus females, as well as decrease in revision risk with increasing age have been reported previously. When interpreting the risk estimates for age groups the impact of life expectancy on revision risk should be taken into consideration since older patients will experience death before revision more often than younger patients. Nevertheless, it has been reported previously that the Kaplan-Meier method substantially overestimated the risk of revision compared to estimates using competing risk methods particularly in the group with the highest incidence of the competing risk of death. ${ }^{30}$

The higher revision risk for uncemented implants compared to cemented implants found in our study agrees with findings from Sweden, New Zealand, and Norway. ${ }^{11,27,31}$ These findings have resulted in change in surgeon behavior and seldom use of uncemented implants in Sweden (close to $0 \%),{ }^{27}$ whereas in Norway, $20 \%$ of femur components and $10 \%$ of tibia components are still uncemented. ${ }^{11}$ Use of uncemented implants in Denmark ${ }^{32}$ and in New Zealand ${ }^{31}$ has decreased continuously for the past several years, ${ }^{9}$ being 
less than 5\% in 2010. On the other hand, reports from knee registries in Australia ${ }^{33}$ and England ${ }^{28}$ found no difference between cemented and uncemented concepts. Uncemented implants have been used in 5\% of the knee replacements in England, whereas 25\% of implants in Australia are uncemented. Comparing the cemented versus uncemented analyses across countries may be challenging due to the large variety of brands of implants and many possible combinations. Havelin et al showed that only three total brands and one unicompartmental brand were common in Norway, Sweden and Denmark, and that at least 50 different tibia and 50 different femur brands have been used in each country. ${ }^{34}$ Thus, it is important to know which brand combinations have been the basis for cemented versus uncemented analyses in order to interpret the results. More detailed separate analyses on specific combinations of implant brands, on more homogenous patients groups, focusing solely on implants with uncemented tibia or uncemented femur components could be useful to clarify this issue. Further, it is still unclear whether differences between uncemented and cemented implants are related to follow-up time after the surgery since differences have been seen after long-term follow-up but not after the short-term follow-up period. ${ }^{33}$

Contrary to reports from the Swedish and the Norwegian knee arthroplasty registries, we found no improvement in overall implant survival with time. This could be related to changes in and the variety of implant brands used over time in these countries, as mentioned above. Further, use of patellar button for total knee arthroplasty, a well-known risk factor for revision ${ }^{11}$ is more popular in Denmark than in Sweden and Norway. ${ }^{35}$ Lower surgery time and a lower proportion of osteoarthritis patients in Denmark compared to Sweden and Norway could also in part explain the discrepancy in implant survival.

\section{Conclusion}

The DKR is a potentially valuable tool for quality improvement and research in the different fields of knee arthroplasty surgery. ${ }^{32}$ Recent collaboration and data linkage with other Scandinavian knee registries might further contribute to quality improvement and understanding of differences in knee arthroplasty surgery between countries.

\section{Acknowledgments}

ABP participated in the design, interpretation of data, drafting and revising of the manuscript. FM carried out the analyses and critically revised the manuscript. AO and HMS participated in the design, interpretation of data, and critically revised the manuscript. All authors read and approved the final manuscript. The authors wish to thank the orthopedic surgeons at all hospitals in Denmark for cooperation on the Danish Knee Arthroplasty Registry.

\section{Disclosure}

The authors report no conflicts of interest in this work.

\section{References}

1 Frank L. Epidemiology. When an entire country is a cohort. Science. 2000;287(5462):2398-2399.

2. Charnley J. The long-term results of low-friction arthroplasty of the hip performed as a primary intervention. J Bone Joint Surg Br. 1972;54(1): 61-76.

3. Insall JN, Dorr LD, Scott RD, Scott WN. Rationale of the Knee Society clinical rating system. Clin Orthop Relat Res. 1989;(248):13-14.

4. Pedersen CB, Gotzsche H, Moller JO, Mortensen PB. The Danish Civil Registration System. A cohort of eight million persons. Dan Med Bull. 2006;53(4):441-449.

5. Thygesen SK, Christiansen CF, Christensen S, Lash TL, Sorensen HT. The predictive value of ICD-10 diagnostic coding used to assess Charlson comorbidity index conditions in the population-based Danish National Registry of Patients. BMC Med Res Methodol. 2011;11:83.

6. Pedersen AB, Mehnert F, Johnsen SP, Husted S, Sorensen HT. Venous thromboembolism in patients having knee replacement and receiving thromboprophylaxis: a Danish population-based follow-up study. J Bone Joint Surg Am. 2011;93(14):1281-1287.

7. Statistics Denmark. The StatBank Denmark. 2011. Available from: http://www.statbank.dk/statbank5a/default.asp?w=1280. Accessed November 1, 2011.

8. Espehaug B, Furnes O, Havelin LI, Engesaeter LB, Vollset SE, Kindseth O. Registration completeness in the Norwegian Arthroplasty Register. Acta Orthop. 2006;77(1):49-56.

9. Knutson K, Lewold S, Robertsson O, Lidgren L. The Swedish knee arthroplasty register. A nation-wide study of 30,003 knees 1976-1992. Acta Orthop Scand. 1994;65(4):375-386.

10. Robertsson O, Dunbar M, Knutson K, Lewold S, Lidgren L. Validation of the Swedish Knee Arthroplasty Register: a postal survey regarding 30,376 knees operated on between 1975 and 1995. Acta Orthop Scand. 1999;70(5):467-472.

11. Helse-Bergen HF. Nasjonalt Kompetansesenter for Leddproteser. Rapport 2011 [The Norwegian Arthroplasty Register. Report 2011]. Available from: http://www.haukeland.no/nrl/Rapporter/ Rapport2008.pdf. Accessed November 1, 2011. Norwegian.

12. Kurtz S, Mowat F, Ong K, Chan N, Lau E, Halpern M. Prevalence of primary and revision total hip and knee arthroplasty in the United States from 1990 through 2002. J Bone Joint Surg Am. 2005;87(7): 1487-1497.

13. Robertsson O, Dunbar MJ, Knutson K, Lidgren L. Past incidence and future demand for knee arthroplasty in Sweden: a report from the Swedish Knee Arthroplasty Register regarding the effect of past and future population changes on the number of arthroplasties performed. Acta Orthop Scand. 2000;71(4):376-380.

14. Kurtz S, Ong K, Lau E, Mowat F, Halpern M. Projections of primary and revision hip and knee arthroplasty in the United States from 2005 to 2030. J Bone Joint Surg Am. 2007;89(4):780-785.

15. Fevang BT, Lie SA, Havelin LI, Engesaeter LB, Furnes O. Reduction in orthopedic surgery among patients with chronic inflammatory joint disease in Norway, 1994-2004. Arthritis Rheum. 2007;57(3):529-532.

16. Shichikawa $\mathrm{K}$, Inoue $\mathrm{K}$, Hirota $\mathrm{S}$, et al. Changes in the incidence and prevalence of rheumatoid arthritis in Kamitonda, Wakayama, Japan, 1965-1996. Ann Rheum Dis. 1999;58(12):751-756. 
17. Weiss RJ, Stark A, Wick MC, Ehlin A, Palmblad K, Wretenberg P. Orthopaedic surgery of the lower limbs in 49,802 rheumatoid arthritis patients: results from the Swedish National Inpatient Registry during 1987 to 2001. Ann Rheum Dis. 2006;65(3):335-341.

18. Dale H, Hallan G, Hallan G, Espehaug B, Havelin LI, Engesaeter LB. Increasing risk of revision due to deep infection after hip arthroplasty. Acta Orthop. 2009;80(6):639-645.

19. Jamsen E, Furnes O, Engesaeter LB, et al. Prevention of deep infection in joint replacement surgery. Acta Orthop. 2010;81(6):660-666.

20. Pedersen AB, Svendsson JE, Johnsen SP, Riis A, Overgaard S. Risk factors for revision due to infection after primary total hip arthroplasty. A population-based study of 80,756 primary procedures in the Danish Hip Arthroplasty Registry. Acta Orthop. 2010;81(5):542-547.

21. Paxton EW, Furnes O, Namba RS, Inacio MC, Fenstad AM, Havelin LI. Comparison of the norwegian knee arthroplasty register and a United States arthroplasty registry. J Bone Joint Surg Am. 2011;93 Suppl 3: 20-30.

22. Grann AF, Erichsen R, Nielsen AG, Froslev T, Thomsen RW. Existing data sources for clinical epidemiology: The clinical laboratory information system (LABKA) research database at Aarhus University, Denmark. Clin Epidemiol. 2011;3:133-138.

23. Schonheyder HC, Sogaard M. Existing data sources for clinical epidemiology: The North Denmark Bacteremia Research Database. Clin Epidemiol. 2010;2:171-178.

24. Cushner F, Agnelli G, FitzGerald G, Warwick D. Complications and functional outcomes after total hip arthroplasty and total knee arthroplasty: results from the Global Orthopaedic Registry (GLORY). Am J Orthop (Belle Mead NJ). 2010;39(Suppl 9):22-28.

25. Husted H, Holm G, Rud K, et al. Length of stay after primary total hip and knee arthroplasty in Denmark, 2001-2003. Ugeskr Laeger. 2006;168(3):276-279.

26. Lee AY, Hirsh J. Diagnosis and treatment of venous thromboembolism. Annu Rev Med. 2002;53:15-33.
27. The Swedish Knee Arthroplasty Register. Annual Report 2011. Available from: http://www.knee.nko.se/english/online/uploadedFiles/115 SKAR2011_Eng1.0.pdf. Accessed March 28, 2012.

28. National Joint Registry for England and Wales. 8th Annual Report 2011. Available from: http://www.njrcentre.org.uk/NjrCentre/Portals/0/ Documents/NJR\%208th\%20Annual\%20Report\%202011.pdf. Accessed March 28, 2012.

29. Jamsen E, Huhtala H, Puolakka T, Moilanen T. Risk factors for infection after knee arthroplasty. A register-based analysis of 43,149 cases J Bone Joint Surg Am. 2009;91(1):38-47.

30. Gillam MH, Ryan P, Graves SE, Miller LN, de Steiger RN, Salter A. Competing risks survival analysis applied to data from the Australian Orthopaedic Association National Joint Replacement Registry. Acta Orthop. 2010;81(5):548-555.

31. New Zealand Joint Registry. New Zealand Orthopaedic Association Twelve Year Report: January 1999 to December 2010. October 2011. Available from: http://www.cdhb.govt.nz/njr/reports/A2D65CA3.pdf. Accessed March 28, 2012.

32. Dansk Knæalloplastik Register. Årsrapport 2011. [Annual report 2011]. Available from: http://www.knee.dk/groups/dkr/pdf/CR16mO9dRluCriUt4i4HOUB4uchIuTR3/gpcDEoiueLD3EGAr.pdf. Accessed March 28, 2012. Danish

33. Australian Orthopaedic Association. National Joint Replacement Registry. Annual Report 2011. Available from: http://www.dmac adelaide.edu.au/aoanjrr/documents/AnnualReports2011/AnnualReport_2011_WebVersion.pdf. Accessed March 28, 2012.

34. Havelin LI, Fenstad AM, Salomonsson R, et al. The Nordic Arthroplasty Register Association: a unique collaboration between 3 national hip arthroplasty registries with 280,201 THRs. Acta Orthop. 2009;80(4):393-401.

35. Robertsson O, Bizjajeva S, Fenstad AM, et al. Knee arthroplasty in Denmark, Norway and Sweden. Acta Orthop. 2010;81(1):82-89.
Clinical Epidemiology

\section{Publish your work in this journal}

Clinical Epidemiology is an international, peer-reviewed, open access journal focusing on disease and drug epidemiology, identification of risk factors and screening procedures to develop optimal preventative initiatives and programs. Specific topics include: diagnosis, prognosis, treatment, screening, prevention, risk factor modification, systematic

\section{Dovepress}

reviews, risk \& safety of medical interventions, epidemiology \& biostatical methods, evaluation of guidelines, translational medicine, health policies \& economic evaluations. The manuscript management system is completely online and includes a very quick and fair peer-review system, which is all easy to use. 